\title{
Ethnicity-based fetal growth charts could reduce inductions and elective cesarean sections
}

\author{
- Cite as: CMAJ 2018 November 12;190:E1343-4. doi: 10.1503/cmaj.109-5670
}

Posted on cmajnews.com on Oct. 24, 2018.

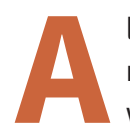

liya Khatri was 36 weeks pregnant with her first child when she was told that her baby was small for gestational age. Immediate induction was recommended.

She wondered whether her and her husband's Indian ethnicity was properly taken into account. "They said that considering my descent, the baby could be smaller, but there didn't seem to be anything on paper, anything scientific, about how much smaller," she recalled. Burhan's baby was induced and born healthy six years ago, but breastfeeding was always difficult, and Burhan thinks the early birth may be to blame.

"I do hear very commonly that induction is offered to women in my community because the babies are measuring small ... but if you're pitting them against a higher scale, obviously they're going to measure smaller," she says.

Whether ethnicity should change fetal growth expectations is a heated debate in the medical community, not just in Canada, but internationally.

The debate has repercussions for immigrant mothers across the country. Currently, obstetricians in Canada use a standard birthweight chart to measure fetal growth. If country of origin or ethnicitybased growth charts were used, many immigrant babies now considered small for gestational age would be considered in the normal range, according to Dr. Joel Ray, an obstetrical medicine physician and scientist at St. Michael's Hospital. That would mean fewer inductions and elective cesarean sections, as doctors often suggest intervention when growth restriction is suspected.

Others argue, however, that decisions about fetal growth shouldn't be based on ethnicity or region of origin at all. Dr. José Villar, codirector of the Oxford Maternal and Perinatal Health Institute, says there should be one international birthweight chart, rather than the current country-bycountry charts.

The evidence on birthweight and ethnicity is open to interpretation. Villar's INTERGROWTH-21st project found that, once factors that affect fetal growth (including poor nutrition, poverty and infections) were excluded, skeletal growth patterns were similar across eight regions of the world. The differences between the sites in the length and head circumference of the babies at birth amounted to $2 \%-3.5 \%$.
But Ray argues that Villar's study was too limiting; it excluded around $70 \%$ of mothers from the study due to physical or environmental factors that could affect fetal growth. "The selected women were so healthy, it's improbable that they'll ever represent their own, or any, ethnic group," says Ray.

Villar disagrees, saying that if there were genetic differences in baby size at the population level, then substantive differences should be seen across regions among the healthiest segment of the population. "There is no evidence that the many genes that control human growth are related to the few genes that control

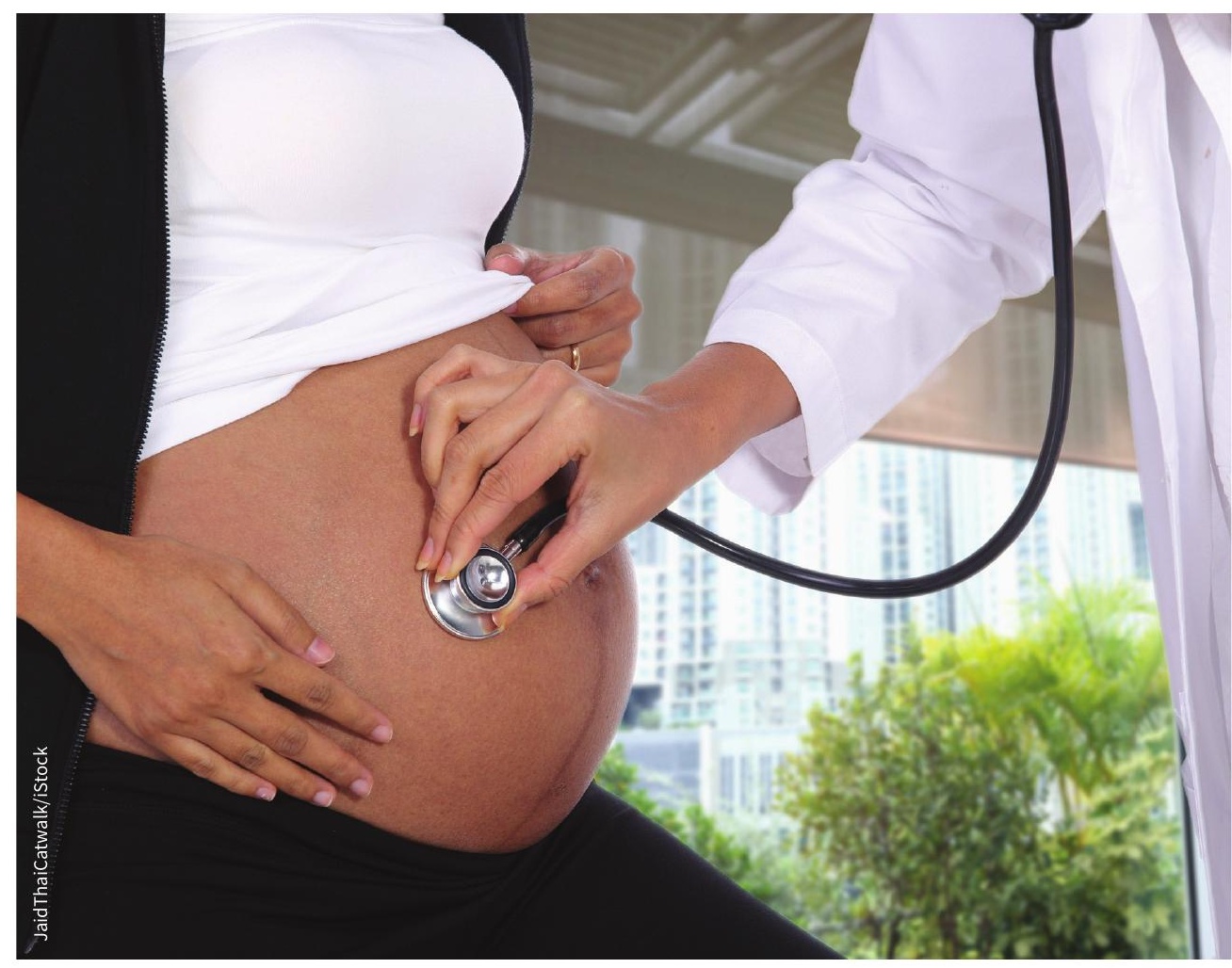

If country of origin or ethnicity-based fetal growth charts were used in Canada, many immigrant babies considered small for gestational age would be considered in the normal range. 
skin colour or the shape of the nose, for example," he says.

Ray's 2014 CMAJ study looked at birthweights of more than 32000 babies born to immigrant women in Toronto and found that the Canadian charts categorized an additional 20431 babies as small for gestational age, compared to growth charts specific to the mother's region of origin. The study also showed that "small" babies born to immigrant mothers had much lower health risks, like prolonged hospital stay and need for ventilation, than SGA babies who were small for gestational age and born to nonimmigrant mothers.

"In Ontario, we see clear birthweight differences [between immigrant populations], and we don't think it's related to smoking, alcohol use or suboptimal nutrition," says Ray. "Their babies are different sizes at birth."

Dr. Ori Nevo, maternal fetal medicine specialist in high-risk pregnancy in the Sunnybrook Women and Babies Program, says that incorporating growth charts that take into account the region of origin would be difficult in practice, especially in multicultural cities. "In Toronto, we have so many mixedrace couples and even the background of the mother can be mixed, so it's becoming complicated," he says. He points out there isn't enough evidence about birthweights of babies born to immigrant parents, including whether the amount of time spent in Canada affects birthweight. In addition, says Nevo, decisions about induction are often made in "a gray zone," where the mother's health, the parents' size and other difficult-tomeasure factors need to be considered.

Wendy Glauser, Toronto, Ont. 